\title{
Preface: Linking landscape organisation and hydrological functioning: from hypotheses and observations to concepts, models and understanding
}

\author{
Conrad Jackisch $^{1}$, Sibylle K. Hassler ${ }^{2}$, Tobias L. Hohenbrink ${ }^{3}$, Theresa Blume ${ }^{4}$, Hjalmar Laudon ${ }^{5}$, \\ Hilary McMillan ${ }^{6}$, Patricia Saco ${ }^{7}$, and Loes van Schaik ${ }^{8}$ \\ ${ }^{1}$ Faculty of Geosciences, Geoengineering and Mining, Technische Universität Bergakademie Freiberg, \\ Agricolastraße 22, 09599 Freiberg, Germany \\ ${ }^{2}$ Institute of Water and River Basin Management, Karlsruhe Institute of Technology (KIT), \\ Kaiserstraße 12, 76131 Karlsruhe, Germany \\ ${ }^{3}$ Technische Universität Braunschweig, Institute of Geoecology, Dept. Soil Science and Soil Physics, \\ Langer Kamp 19c, 38106 Braunschweig, Germany \\ ${ }^{4}$ GFZ German Research Centre for Geosciences, Section Hydrology, Telegrafenberg, 14473 Potsdam, Germany \\ ${ }^{5}$ Department of Forest Ecology and Management, Swedish University of Agricultural Sciences (SLU), Umeå 901 83, Sweden \\ ${ }^{6}$ Department of Geography, San Diego State University, San Diego, CA 92184-4493, California \\ ${ }^{7}$ School of Engineering and Centre for Water Security and Environmental Sustainability, \\ University of Newcastle, Callaghan, 2308, Australia \\ ${ }^{8}$ Wageningen University and Research, Department of Environmental Sciences, Soil Physics and Land Management, \\ Droevendaalsesteeg 3, 6708PB Wageningen, the Netherlands
}

Correspondence: Conrad Jackisch (conrad.jackisch@tbt.tu-freiberg.de)

Published: 28 September 2021

\begin{abstract}
The link between landscape properties and hydrological functioning is the very foundation of hydrological sciences. The fundamental perception that landscape organisation and its hydrological and biogeochemical processes co-develop is often discussed. However, different landscape characteristics and hydrological processes interact in complex ways. Hence, the causal links between both are usually not directly deducible from our observations. So far no common concepts have been established to connect observations, properties and functions at and between different scales.

This special issue hosts a broad set of original studies indicating the current state and progress in our understanding of different facets of dynamic hydrological systems across various scales. It is organised as a joint special issue in HESS and ESSD, with the purpose of providing the scientific insights in combination with the underlying data sets and study design. While the individual studies contribute to distinct aspects of the link between landscape characteristics and hy-
\end{abstract}

drological functioning, it remained difficult to compile their specific findings to more general conclusions.

In this preface, we summarise the contributions. In the search for ways to synthesise these individual studies to the overall topic of linking landscape organisation and hydrological functioning, we suggest four major points how this process could be facilitated in the future: (i) formulating clear and testable research hypotheses, (ii) establishing appropriate sampling designs to test these hypotheses, (iii) fully providing the data and code, and (iv) clarifying and communicating scales of observations and concepts as well as scale transfers.

\section{Introduction}

The challenge to unify our understanding of landscape organisation and its hydrological functioning is a long-standing issue in hydrological sciences - maybe as old as our disci- 
pline itself. In this we search for the influence of the spatial arrangement of landscape elements on fluxes, storage, mixing and release of water, solutes and energy and vice versa (Grayson and Blöschl, 2000). These interactions of landscape organisation and hydrological functioning exist at different scales in space and time (Fan et al., 2019). Uncountable observations, experiments and models have advanced our understanding of the soil-vegetation-atmosphere system. Landscape organisation appearing as self-similar patterns (Rodriguez-Iturbe and Rinaldo, 1997), structured flow paths (Flury et al., 1994; Nimmo, 2016), thermodynamic optimality (Kleidon and Schymanski, 2008; Phillips, 2016) and other forms has always driven approaches to derive the relationship between the dominating hydrological and biogeochemical processes (Lin, 2010; Laudon and Sponseller, 2018) and identifiable landscape signatures (Gharari et al., 2011). Likewise, we can find a plethora of concepts about hydrological functioning aiming to explain landscape organisation based on self-reinforcing patterns out of smaller-scale heterogeneity (Hohenbrink and Lischeid, 2015; Berkowitz and Zehe, 2020), the transition of their impact through scales (Vogel and Roth, 1998) and their dynamic similarity (Loritz et al., 2018).

The universal scientific approach to test hypotheses based on concepts, observations and models is indisputably one of most important foundations for deriving understanding (e.g. Jaynes, 2003; Pfister and Kirchner, 2017; Beven, 2019a). However, complex interactions of processes across spatiotemporal scales and across different elements of landscapes establish severe challenges to follow this blueprint. Demands for practical solutions to real-world problems set reasonable constraints to such airy framings. One result of this conflict between scientific rigour and practicality is an excessive amount of sophisticated methods in the different hydrological subdisciplines. However, it remains difficult to combine these approaches into an integral system understanding, despite good suggestions for unifying theories (e.g. Reggiani et al., 1998; Beven, 2006; Sivapalan, 2006). Instead, hydrologists have become aware of the limitations of predictions (Beven, 1993) and multiple sources of uncertainty in increasingly complex hydrological concepts, models and data (Nearing et al., 2016). The central role of data in advancing hydrological sciences (Beven, 2019b) is deeply connected with the various concepts for better predictions of hydrological systems under change (Ehret et al., 2014; Wagener et al., 2010).

Likely instigated by the initiative to predict hydrology in ungauged basins (Sivapalan, 2003; Blöschl et al., 2013; Hrachowitz et al., 2013), several suggestions to unify approaches, to extend them across scales, and to understand processes across disciplines and system domains have been made at the beginning of the millennium (Sivapalan, 2006). In complementary avenues, the debate about hydropedology (Lin et al., 2006) urged our community to synthesise knowledge and approaches towards a "critical zone science" across disciplines (Brantley et al., 2007) to make them applicable to ungauged situations under changing land use and climate or even on other planets.

Our special issue follows the basic perception that landscape organisation and hydrological functioning are two sides of the same coin and that the ideal of interdisciplinary hydrology can guide our research. A large proportion of its motivation is rooted in the discussions within the CAOS research unit (From Catchments as Organised Systems to Models Based on Functional Units, Zehe et al., 2014). As the availability, consistency and transparency of measurement data form the very foundation for building this understanding, we explicitly invited companion papers in HESS and ESSD to the special issue to underline the role of data in the research for concepts of hydrological landscape functioning.

In this preface we give an overview of the contributions regarding their research focus and main results. We emphasise the challenge of addressing hydrological functioning in landscapes and propose a possible way of progressing in this complex topic, relating to testable research hypotheses, sampling design, open data and open code and communication of scale and scale transfers.

\section{Contributions to this special issue}

The 16 author teams contributing to this special issue provided a cross-discipline glimpse into different facets of hydrological research. Altogether the contributions cover a very broad range of scales, spatially ranging from the plot scale to the large catchment scale and temporally ranging from minutes to 10 millennia. The thematic foci of the contributions can be loosely assigned to the five subdisciplines hydrometeorology, catchment hydrology, riparian zone hydrology, ecohydrology and soil hydrology, keeping in mind that most papers have overlaps with other subdisciplines. In Fig. 1 the contributions are assigned to their respective landscape elements. However, the extent of their findings reach beyond the illustrated points.

The contributions of this special issue are very diverse in many respects, but they share one overarching objective: learning more about the spatio-temporal organisation of hydrological functioning. In this section we introduce all contributions arranged according to their correspondent (approximate) subdiscipline and summarise their key messages.

Hydrological functioning of landscapes can be addressed at a large range of spatial and temporal scales and within many different subdisciplines. In soil hydrology, soil maps are frequently used as an input for hydrological and land surface models. However, the development of these maps poses a series of challenges with regard to the spatial coverage, the reliability at the landscape scale and the conversion of mapped soil properties into respective model parameters, which leads to uncertainty in the maps and complicates their use in hydrological modelling. Kmoch et al. 


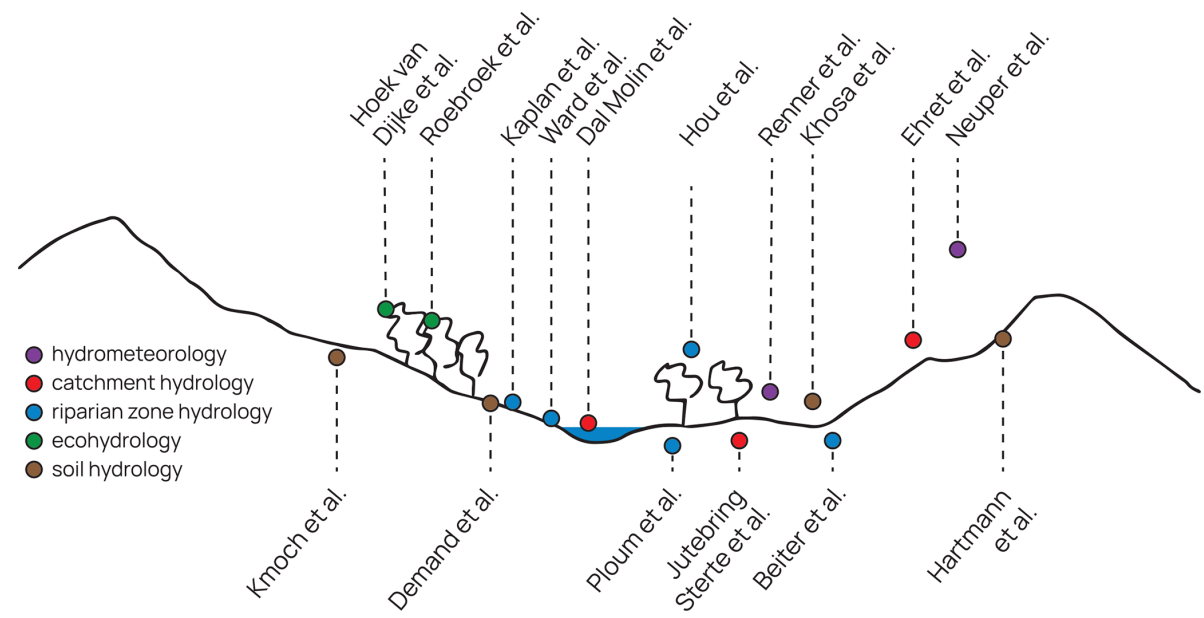

Figure 1. Subdiscipline and landscape elements of the contributions.

(2021) approached this challenge by developing a digital hydrological soil map for Estonia based on soil characteristics, landscape properties and data fusion. Today, remotesensing products are often used to support large-scale analysis of spatio-temporal patterns in landscapes. For soil moisture, Khosa et al. (2020) showed how using model-assisted soil moisture estimates could reveal the seasonal pattern in a semi-arid setting. On a much smaller scale, the sequence of sensor responses from a large set of soil moisture sensor profiles was used to infer seasonal and spatial patterns of preferential flow and connected to geological and land cover influences by Demand et al. (2019). Finally, Hartmann et al. $(2020 \mathrm{~b}$, a) approached the evolution of soil hydrological functioning based on measurements of soil physical properties and infiltration experiments in alpine periglacial moraines of different ages, generating insight into the interplay of physical site conditions and vegetation development, leading to changing soil properties and flow paths.

Focusing on the ecoyhdrological effect of vegetation shaping the exchange of water and energy at the land surface, the ubiquity of remotely sensed indices for land surface water fluxes was found to be limited. In a temperate setting the Normalised Difference Vegetation Index was challenged with sap velocity measurements, raising awareness for a careful evaluation of the applicability of the underlying assumptions for a specific ecosystem and scale (Hoek van Dijke et al., 2019). At the global scale, an analysis of hydrological controls on forest growth highlights access to subsurface water as a major factor in vegetation growth (Roebroek et al., 2020). The authors extend the Budyko concept of water and energy limits with landscape characteristics.

Coming from a hydrometeorological perspective and focusing on temporal dynamics, Renner et al. (2019) studied the phase lag in diurnal evapotranspiration process modelling. Their findings propose limits in Penman-Monteith approaches at a sub-daily scale, which can be avoided when re- ferring to the surface-to-air temperature gradient instead of vapour pressure deficit approaches. A different form of water and energy exchange at the land surface was examined by Neuper and Ehret (2019) with a detailed analysis of distributed precipitation estimation from radar measurements. They found that relationships of radar reflectivity and ground rainfall, which are specific to season and synoptic weather situation, can substantially improve quantitative precipitation estimation from weather radar data.

Spatially distributed data of precipitation as well as snowrelated processes and landscape features such as geology were found to be crucial for precise predictions in catchment hydrology (Dal Molin et al., 2020). They developed a two-stage approach with explicit model experiments testing the effect of the data on different catchment indices to guide a rainfall-runoff model setup based on commonly available data also for ungauged basins. Since in hydrological modelling the self-similarity of space-time patterns of model elements can reduce the required input data, can increase model performance and can be interpreted with respect to main process controls, Ehret et al. (2020) designed a dynamical clustering of distributed model elements into grouped response units. Besides the positive effects on computational performance, their approach enables an analysis of information gains and resolution requirements for distributed models. Having a large database of monitoring data available, hydrological pathways and a detailed picture of how landscape factors regulate travel time distributions could be revealed from measurements of the dynamics of groundwater and stream chemistry in nested catchments (Jutebring Sterte et al., 2021).

Riparian zones as biogeochemical hotspots require a joint approach to physical, chemical and biological system dynamics. Based on an analysis of hydrological pathways of dissolved organic carbon, it was shown how specific delicate areas can massively alter the hydrological pathways 
and system properties when disturbed (Ploum et al., 2020). Analysing a massive database of solute tracer studies of riparian exchange fluxes across basin scales and system domains, Ward et al. (2019b) identified distinct spatial patterns but large temporal diversity in riparian zones. This suggests severe limits to space-for-time substitution approaches (Ward et al., 2019a). Monitoring surface stream connectivity and intermittency with different techniques revealed temporal and spatial dynamics of the stream network and provided information about hydrological functioning in a mesoscale catchment (Kaplan et al., 2019). When compiled as intermittency maps, the data were used to evaluate landscape predictors: terrain metrics were informative during wet periods, while soil drainage and storage properties govern the patterns of drier periods (Kaplan et al., 2020). Landscape organisation is often manifested in connectivity patterns of hillslopes and streams. Beiter et al. (2020) found that soil structure can reveal how this connection takes place, and complementary dynamics of shallow ground water table dynamics add information about when this connection becomes active. Finally, at a much larger scale, the identification of hydromorphological attributes from remotely sensed data about floodplain dynamics were used to address spatio-temporal changes in hydrological processes for river reaches (Hou et al., 2019).

\section{Suggestions towards facilitating comprehensive, reproducible and transferable findings}

The challenge to fundamentally address and advance our understanding of the link between landscape properties and organisation with its functioning can hardly be tackled within a single study. Each of the contributions submitted to this special issue covers a small piece of the big picture. While discussing the papers in this special issue, we identified several aspects which might help to extend the scientific value of the research beyond the specific studies.

\subsection{Promoting testable research hypotheses and sampling design}

Hypothesis testing is a key methodological feature of science (e.g. Mizrahi, 2020; Pfister and Kirchner, 2017). Defining testable hypotheses about hydrological functioning in landscapes, however, appears to be a complicated task. A possible explanation for this challenge is that hydrological research aims to gain functional understanding about very complex environmental systems with non-linear dynamics and organised complexity (Dooge, 2005). This complexity entails the difficulty of formulating comprehensive hypotheses about the hydrological functioning, which consequently often results in very vague conclusions (Bracken et al., 2013).

Directly linked to addressing a sound scientific hypothesis is developing the appropriate sampling design. As an environmental science confronted with apparently ever-unique settings, one might note a slight tendency in hydrology to adhere to descriptive concepts of physical geography as a basis for sampling. There are good reasons to adhere to practical constraints and classical conceptual models, but this hampers advances in defining precise and testable hypotheses (Gupta and Nearing, 2014). While viable solutions to specific problems may be found without a deep system-theoretical background, it is difficult to align data and insights from such studies with a broader perspective. However, the crux of the matter is that a sound understanding of hydrological functioning is the very basis for meaningful testable hypotheses with appropriate sampling designs, which then in turn lead to a better understanding. Obviously, formulating and testing hypotheses which go beyond the actual practical problems and also address the complex scale-dependent interactions demand substantial additional effort. However, to achieve comprehensive hydrological understanding and advance predictability of environmental systems under global change (Ehret et al., 2014), the extra effort appears worthwhile.

Joining forces in interdisciplinary collaboration is one way to address this challenge, i.e. sharing the task of studying the complex interactions of the different influences on hydrological functioning in landscapes. Examples in this special issue are Ward et al. (2019a), who combined diverse data for riparian exchange fluxes in the H. J. Andrews Experimental Forest, or also Jutebring Sterte et al. (2021), who can benefit from a massive monitoring effort in the Krycklan catchment. The CAOS research unit (Zehe et al., 2014) - which was a starting point for initiating this special issue - explicitly defined "functional units" as the central research object and addressed it with a large interdisciplinary monitoring effort in the Attert basin in Luxembourg (e.g. Renner et al., 2019; Hoek van Dijke et al., 2019; Loritz et al., 2017; Jackisch et al., 2017). However, the challenge of defining the joint hypotheses to test this functioning and adapting the sampling designs accordingly also remained unsolved. Nevertheless, the potential in addressing these questions jointly within a research collaboration should not be discarded because of the collateral complexity in collaboration that comes with extended research groups.

\subsection{Merits of full data and code availability}

The intention behind initiating this special issue jointly in HESS and ESSD was to emphasise the role of open data for progress in hydrological research. Reproducibility is seen as one of the basic principles of good scientific practice and requires access to the data and code that were used to produce the respective findings (Hutton et al., 2016; Laudon and Taberman, 2016). For data management and stewardship, widely accepted rules have been defined in the FAIR principles: findability, accessibility, interoperability and reusability (Wilkinson et al., 2016). Furthermore, sharing the data and code is expected to increase appreciation for experimental 
Table 1. Overview of access to data and code for the studies in this special issue. ${ }^{*}$ Three articles have companion papers in both journals. Some studies link to more than one data source. Completeness of provided data and code is not considered.

\begin{tabular}{lrr}
\hline Papers with ... & HESS & ESSD \\
\hline access to data over repository & 11 & 5 \\
access to data over public web sites & 7 & 0 \\
full or partial data upon request & 7 & 0 \\
access to code over repository & 6 & 1 \\
no access to code stated & 8 & 4 \\
\hline Total no. of contributions & 14 & $5^{*}$ \\
\hline
\end{tabular}

work and propel utilisation of the data as well as advance the used methods (Blume et al., 2017).

In this special issue 10 out of 14 contributions in HESS provide a persistent open data repository reference for parts or all of the used data. Three articles have a companion paper in ESSD, which provide an elaborate explanation of the data. Seven contributions refer to websites as public sources of the used data. Seven state full or partial data availability upon request from the authors or other sources.

Code availability is more scarce. Six out of all 19 contributions report repositories for their code. In one case, the code is offered on request. In most publications of this special issue, no statement about code availability is given. Table 1 gives an overview. Compared to the results of an elaborate review of data and code availability of 360 articles published in 2017 (Stagge et al., 2019), these results are above average data and code availability. It is clear that in some cases sharing the study-specific data collection appears to still be obstructed by specific restraints on parts of the data, such as web-based repositories without open licenses (Rosenberg et al., 2020). Additionally, often only partial data are provided, which makes reproducibility of the study results difficult.

It appears to still be an exception that all data used in a study, including the code to reproduce the results, are published alongside the paper. Reasons for this are a lack of time and personnel resources for this meticulous task in project funds (Blume et al., 2018) as well as a lack of prioritisation and data management skills. Moreover, quality control of the data and the code is an ongoing challenge in hydrological research.

In our special issue we find a wide range of how data and code are presented. This complicates joint progress towards understanding the bigger picture. Learning from existing data, adapting well-described methods and reusing analytical code, however, permit more integral analyses by combining previous efforts. Linking landscape organisation and hydrological functioning requires such analyses. After reviewing the contributions to the special issue, we believe that explicitly demanding consistent and complete access to data and code in the call would have enabled more progress in the topic. Addressing landscape organisation in the future would benefit from improved reproducibility of research along the recommendations of Rosenberg et al. (2020) and Hall et al. (2021).

\subsection{Proposal for transparency about scales and concepts}

The contributions to this special issue naturally cover a spectrum of spatial and temporal scales connected to landscape organisation and hydrological functioning. A proper identification of these scales (in the sense of the scale triplet, Blöschl and Sivapalan, 1995) relating to the employed methods, the obtained data, conceptual models (Wagener et al., 2020; Gupta et al., 2012) and the concluded findings is essential for a good understanding and reporting of the results. After discussing the contributions, we suggest that a clarification of the applied scale transfer is similarly important.

Most studies depict a common scale for their data, concepts and findings - be it diurnal evapotranspiration (Renner et al., 2019), catchment dynamics (Dal Molin et al., 2020), or rainfall quantification (Neuper and Ehret, 2019). Some studies combine aspects of several scales, for example Hartmann et al. (2020a), where short-term infiltration dynamics were linked to long-term soil development, and Hoek van Dijke et al. (2019), where remotely sensed vegetation indices are compared to tree-level sap flow dynamics. Other studies attempt to bridge scales, e.g. when few local point observations are connected to spatially continuous remote-sensing products at larger scales as in Khosa et al. (2020) or when many local point observations are used to infer infiltration processes at smaller scales as in Demand et al. (2019).

Bridging scales requires assumptions and connections for the scale transfer (Peters-Lidard et al., 2017). We found large differences in how the studies in our special issue have resolved this issue. In the following we want to examine the scales and scale transfers along three examples. While Neuper and Ehret (2019) explicitly analysed the scale transfer of information at smaller and larger scales for the quantification of weather radar precipitation products (Fig. 2a), Demand et al. (2019) inferred small-scale, longitudinal preferential flow dynamics based on a large number of soil moisture measurements. In the absence of direct observations at the scale of the conclusions, the scale transfer has to rely on a hypothesis (Fig. 2b). As a third example, Hartmann et al. (2020a) used observations at smaller scales to infer on a series of temporal scales as a process-based space-for-time substitution approach (Fig. 2c). In this example, the scale transfer also remains bound to hypotheses.

The contributions to this special issue show a wide range of approaches to address scales and scale transfer of the observations and concepts. As a means to turn the diversity within hydrological research into an improved understanding of the systems across scales, we suggest placing more 
(a) Neuper et al.

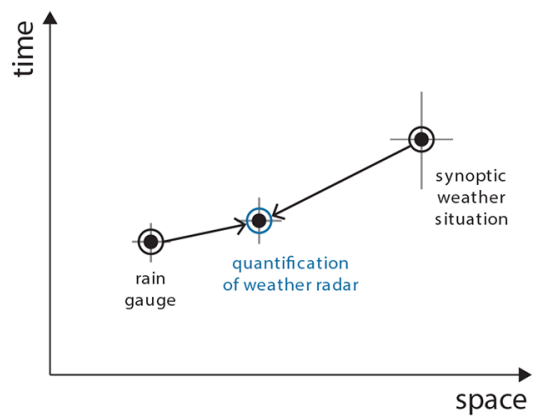

(b) Demand et al.

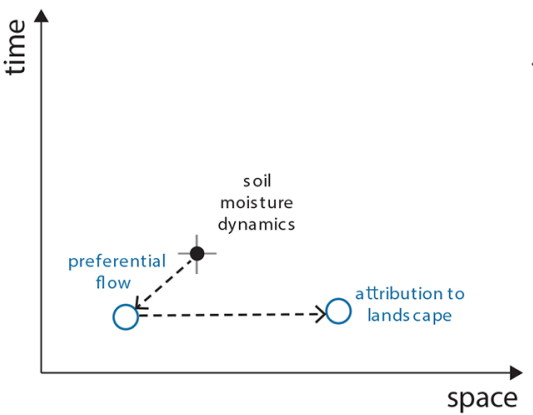

(c) Hartmann et al.

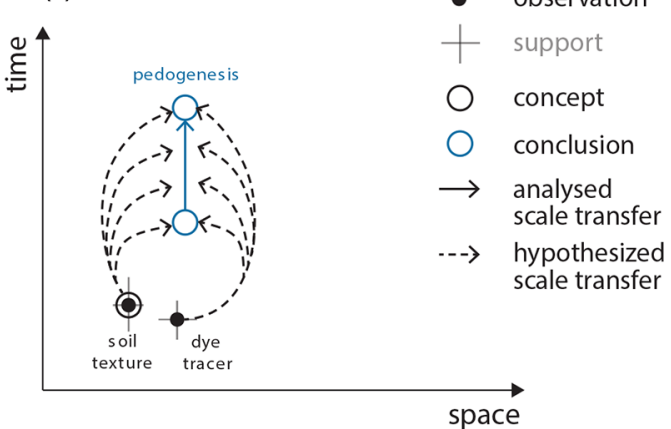

Figure 2. Examples of scales of observations, concepts and conclusions and how scale transfer is addressed.

emphasis on this topic. We propose to communicate a "scales and scaling statement" with each publication, explicitly addressing the scale of both observations and concepts and consequently the scale transfer, to clarify the support of the transfer and the underlying assumptions, e.g. similar to the previous examples and Fig. 2. This transparency could be understood as an essential and self-critical clarification helping to discuss the support of the conclusions and to achieve joint scientific progress.

\section{Conclusions}

Linking landscape organisation and hydrological functioning remains a challenging goal. The complexity originates in the interaction of processes across landscape elements and scales. The individual contributions showed insights into these processes, from point scale to large catchments, from minutes to millennia, and in a range of hydrological subdisciplines. However, we did not advance the overall topic considerably. One reason for this might be the difficulty in combining the results into a meta-analysis, partly due to lack of clarity on hypotheses, sampling design, scales and scaling assumptions.

We propose that significant advances can be achieved when the following points are considered and communicated in an integral manner in future studies:

- formulation of specific and testable research hypotheses about hydrological functioning;

- elaboration of an appropriate sampling design to address these hypotheses;

- provision of all the data and code with each study; and

- clarification of scales and the employed method of scale transfer.

Fulfilling these high standards requires additional effort but is rewarded with enhanced quality, comprehension and transferability of the findings. Only then can the specific pieces that individual studies contribute be compiled to the bigger picture.

Author contributions. CJ, SH, TH and LS jointly discussed the contributions to this special issue and wrote the first draft of this preface. TB, HL, HM and PS provided feedback which was incorporated into the final version.

Competing interests. Some authors are members of the editorial board of Hydrology and Earth System Sciences. The peer-review process was guided by an independent editor, and the authors have also no other competing interests to declare.

Disclaimer. Publisher's note: Copernicus Publications remains neutral with regard to jurisdictional claims in published maps and institutional affiliations.

Special issue statement. This article is part of the special issue "Linking landscape organisation and hydrological functioning: from hypotheses and observations to concepts, models and understanding (HESS/ESSD inter-journal SI)". It is not associated with a conference.

Acknowledgements. The special issue was initiated as a result of vibrant discussions within the CAOS research unit (DFG FOR 1598). We thank all the other guest editors who put in their time and effort to make this special issue possible, namely Thom Boogard, Alexander Gelfan, Pierre Gentine, Alberto Guadagnini, Giulio Iovine, Laurent Pfister, Maik Renner, Shraddhanand Shukla, Lixin Wang and Erwin Zehe. 


\section{References}

Beiter, D., Weiler, M., and Blume, T.: Characterising hillslopestream connectivity with a joint event analysis of stream and groundwater levels, Hydrol. Earth Syst. Sci., 24, 5713-5744, https://doi.org/10.5194/hess-24-5713-2020, 2020.

Berkowitz, B. and Zehe, E.: Surface water and groundwater: unifying conceptualization and quantification of the two water worlds, Hydrol. Earth Syst. Sci., 24, 1831-1858, https://doi.org/10.5194/hess-24-1831-2020, 2020.

Beven, K.: Prophecy, reality and uncertainty in distributed hydrological modelling, Adv. Water Resour., 16, 41-51, https://doi.org/10.1016/0309-1708(93)90028-E, 1993.

Beven, K.: Searching for the Holy Grail of scientific hydrology: $Q_{t}=H(S, R, \Delta t) A$ as closure, Hydrol. Earth Syst. Sci., 10, 609-618, https://doi.org/10.5194/hess-10-609-2006, 2006.

Beven, K.: Towards a methodology for testing models as hypotheses in the inexact sciences, P. Roy. Soc. A, 475, 20180862, https://doi.org/10.1098/rspa.2018.0862, 2019a.

Beven, K.: How to make advances in hydrological modelling, Hydrol. Res., 50, 1481-1494, https://doi.org/10.2166/nh.2019.134, 2019b.

Blöschl, G. and Sivapalan, M.: Scale issues in hydrological modelling: A review, Hydrol. Process., 9, 251-290, https://doi.org/10.1002/hyp.3360090305, 1995.

Blöschl, G., Sivapalan, M., Wagener, T., Viglione, A., and Savenije, H.: Runoff Prediction in Ungauged Basins, in: Synthesis Across Processes, Places and Scales, Cambridge University Press, Cambridge, 978-1107028180, 2013.

Blume, T., van Meerveld, I., and Weiler, M.: The role of experimental work in hydrological sciences - insights from a community survey, Hydrolog. Sci. J., 62, 334-337, https://doi.org/10.1080/02626667.2016.1230675, 2017.

Blume, T., van Meerveld, I., and Weiler, M.: Incentives for field hydrology and data sharing: collaboration and compensation: reply to "A need for incentivizing field hydrology, especially in an era of open data", Hydrolog. Sci. J., 63, 1266-1268, https://doi.org/10.1080/02626667.2018.1495839, 2018.

Bracken, L., Wainwright, J., Ali, G., Tetzlaff, D., Smith, M., Reaney, S., and Roy, A.: Concepts of hydrological connectivity: Research approaches, pathways and future agendas, Earth-Sci. Rev., 119, 17-34, https://doi.org/10.1016/j.earscirev.2013.02.001, 2013.

Brantley, S. L., Goldhaber, M. B., and Ragnarsdottir, K. V.: Crossing Disciplines and Scales to Understand the Critical Zone, Elements, 3, 307-314, https://doi.org/10.2113/gselements.3.5.307, 2007.

Dal Molin, M., Schirmer, M., Zappa, M., and Fenicia, F.: Understanding dominant controls on streamflow spatial variability to set up a semi-distributed hydrological model: the case study of the Thur catchment, Hydrol. Earth Syst. Sci., 24, 1319-1345, https://doi.org/10.5194/hess-24-1319-2020, 2020.

Demand, D., Blume, T., and Weiler, M.: Spatio-temporal relevance and controls of preferential flow at the landscape scale, Hydrol. Earth Syst. Sci., 23, 4869-4889, https://doi.org/10.5194/hess-234869-2019, 2019.

Dooge, J. C. I.: Bringing it all together, Hydrol. Earth Syst. Sci., 9, 3-14, https://doi.org/10.5194/hess-9-3-2005, 2005.

Ehret, U., Gupta, H. V., Sivapalan, M., Weijs, S. V., Schymanski, S. J., Blöschl, G., Gelfan, A. N., Harman, C., Kleidon, A.,
Bogaard, T. A., Wang, D., Wagener, T., Scherer, U., Zehe, E., Bierkens, M. F. P., Di Baldassarre, G., Parajka, J., van Beek, L. P. H., van Griensven, A., Westhoff, M. C., and Winsemius, H. C.: Advancing catchment hydrology to deal with predictions under change, Hydrol. Earth Syst. Sci., 18, 649-671, https://doi.org/10.5194/hess-18-649-2014, 2014.

Ehret, U., van Pruijssen, R., Bortoli, M., Loritz, R., Azmi, E., and Zehe, E.: Adaptive clustering: reducing the computational costs of distributed (hydrological) modelling by exploiting timevariable similarity among model elements, Hydrol. Earth Syst. Sci., 24, 4389-4411, https://doi.org/10.5194/hess-24-4389-2020, 2020.

Fan, Y., Clark, M., Lawrence, D. M., Swenson, S., Band, L. E., Brantley, S. L., Brooks, P. D., Dietrich, W. E., Flores, A., Grant, G., Kirchner, J. W., Mackay, D. S., McDonnell, J. J., Milly, P. C. D., Sullivan, P. L., Tague, C., Ajami, H., Chaney, N., Hartmann, A., Hazenberg, P., McNamara, J., Pelletier, J., Perket, J., Rouholahnejad-Freund, E., Wagener, T., Zeng, X., Beighley, E., Buzan, J., Huang, M., Livneh, B., Mohanty, B. P., Nijssen, B., Safeeq, M., Shen, C., van Verseveld, W., Volk, J., and Yamazaki, D.: Hillslope Hydrology in Global Change Research and Earth System Modeling, Water Resour. Res., 55, 1737-1772, https://doi.org/10.1029/2018WR023903, 2019.

Flury, M., Flühler, H., Jury, W. A., and Leuenberger, J.: Susceptibility of soils to preferential flow of water: A field study, Water Resour. Res., 30, 1945-1954, https://doi.org/10.1029/94WR00871, 1994.

Gharari, S., Hrachowitz, M., Fenicia, F., and Savenije, H. H. G.: Hydrological landscape classification: investigating the performance of HAND based landscape classifications in a central European meso-scale catchment, Hydrol. Earth Syst. Sci., 15, 3275-3291, https://doi.org/10.5194/hess-15-3275-2011, 2011.

Grayson, R. and Blöschl, G.: Spatial Patterns in Catchment Hydrology: Observations and Modelling, Cambridge University Press, Cambridge, 978-0521633161, 2000.

Gupta, H., Clark, M. P., Vrugt, J. A., Abramowitz, G., and Ye, M.: Towards a Comprehensive Assessment of Model Structural Adequacy, Water Resour. Res., 48, 1-40, https://doi.org/10.1029/2011WR011044, 2012.

Gupta, H. V. and Nearing, G. S.: Debates - the future of hydrological sciences: A (common) path forward? Using models and data to learn: A systems theoretic perspective on the future of hydrological science, Water Resour. Res., 50, 5351-5359, https://doi.org/10.1002/2013WR015096, 2014.

Hall, C. A., Saia, S. M., Popp, A. L., Dogulu, N., Schymanski, S. J., Drost, N., van Emmerik, T., and Hut, R.: A Hydrologist's Guide to Open Science, Hydrol. Earth Syst. Sci. Discuss. [preprint], https://doi.org/10.5194/hess-2021-392, in review, 2021.

Hartmann, A., Semenova, E., Weiler, M., and Blume, T.: Field observations of soil hydrological flow path evolution over 10 millennia, Hydrol. Earth Syst. Sci., 24, 3271-3288, https://doi.org/10.5194/hess-24-3271-2020, 2020a.

Hartmann, A., Weiler, M., and Blume, T.: The impact of landscape evolution on soil physics: evolution of soil physical and hydraulic properties along two chronosequences of proglacial moraines, Earth Syst. Sci. Data, 12, 3189-3204, https://doi.org/10.5194/essd-12-3189-2020, 2020b.

Hoek van Dijke, A. J., Mallick, K., Teuling, A. J., Schlerf, M., Machwitz, M., Hassler, S. K., Blume, T., and Herold, 
M.: Does the Normalized Difference Vegetation Index explain spatial and temporal variability in sap velocity in temperate forest ecosystems?, Hydrol. Earth Syst. Sci., 23, 2077-2091, https://doi.org/10.5194/hess-23-2077-2019, 2019.

Hohenbrink, T. L. and Lischeid, G.: Does textural heterogeneity matter? Quantifying transformation of hydrological signals in soils, J. Hydrol., 523, 725-738, https://doi.org/10.1016/j.jhydrol.2015.02.009, 2015.

Hou, J., van Dijk, A. I. J. M., Renzullo, L. J., Vertessy, R. A., and Mueller, N.: Hydromorphological attributes for all Australian river reaches derived from Landsat dynamic inundation remote sensing, Earth Syst. Sci. Data, 11, 1003-1015, https://doi.org/10.5194/essd-11-1003-2019, 2019.

Hrachowitz, M., Savenije, H., Blöschl, G., McDonnell, J., Sivapalan, M., Pomeroy, J., Arheimer, B., Blume, T., Clark, M., Ehret, U., Fenicia, F., Freer, J., Gelfan, A., Gupta, H., Hughes, D., Hut, R., Montanari, A., Pande, S., Tetzlaff, D., Troch, P., Uhlenbrook, S., Wagener, T., Winsemius, H., Woods, R., Zehe, E., and Cudennec, C.: A decade of Predictions in Ungauged Basins (PUB) - a review, Hydrolog. Sci. J., 58, 1198-1255, https://doi.org/10.1080/02626667.2013.803183, 2013.

Hutton, C., Wagener, T., Freer, J., Han, D., Duffy, C., and Arheimer, B.: Most computational hydrology is not reproducible, so is it really science?, Water Resour. Res., 52, 7548-7555, https://doi.org/10.1002/2016WR019285, 2016.

Jackisch, C., Angermann, L., Allroggen, N., Sprenger, M., Blume, T., Tronicke, J., and Zehe, E.: Form and function in hillslope hydrology: in situ imaging and characterization of flowrelevant structures, Hydrol. Earth Syst. Sci., 21, 3749-3775, https://doi.org/10.5194/hess-21-3749-2017, 2017.

Jaynes, E. T.: Probability Theory, Cambridge University Press, Cambridge, 978-0521592710, https://doi.org/10.1017/CBO9780511790423, 2003.

Jutebring Sterte, E., Lidman, F., Lindborg, E., Sjöberg, Y., and Laudon, H.: How catchment characteristics influence hydrological pathways and travel times in a boreal landscape, Hydrol. Earth Syst. Sci., 25, 2133-2158, https://doi.org/10.5194/hess-252133-2021, 2021.

Kaplan, N. H., Sohrt, E., Blume, T., and Weiler, M.: Monitoring ephemeral, intermittent and perennial streamflow: a dataset from 182 sites in the Attert catchment, Luxembourg, Earth Syst. Sci. Data, 11, 1363-1374, https://doi.org/10.5194/essd-11-13632019, 2019.

Kaplan, N. H., Blume, T., and Weiler, M.: Predicting probabilities of streamflow intermittency across a temperate mesoscale catchment, Hydrol. Earth Syst. Sci., 24, 5453-5472, https://doi.org/10.5194/hess-24-5453-2020, 2020.

Khosa, F. V., Mateyisi, M. J., van der Merwe, M. R., Feig, G. T., Engelbrecht, F. A., and Savage, M. J.: Evaluation of soil moisture from CCAM-CABLE simulation, satellite-based models estimates and satellite observations: a case study of Skukuza and Malopeni flux towers, Hydrol. Earth Syst. Sci., 24, 1587-1609, https://doi.org/10.5194/hess-24-1587-2020, 2020.

Kleidon, A. and Schymanski, S.: Thermodynamics and optimality of the water budget on land: A review, Geophys. Res. Lett., 35, L20404, https://doi.org/10.1029/2008GL035393, 2008.

Kmoch, A., Kanal, A., Astover, A., Kull, A., Virro, H., Helm, A., Pärtel, M., Ostonen, I., and Uuemaa, E.: EstSoilEH: a high-resolution eco-hydrological modelling parame- ters dataset for Estonia, Earth Syst. Sci. Data, 13, 83-97, https://doi.org/10.5194/essd-13-83-2021, 2021.

Laudon, H. and Sponseller, R. A.: How landscape organization and scale shape catchment hydrology and biogeochemistry: insights from a long-term catchment study, WIREs Water, 5, e1265, https://doi.org/10.1002/wat2.1265, 2018.

Laudon, H. and Taberman, I.: Data rules: from personal belonging to community goods, Hydrol. Process., 30, 1978-1981, https://doi.org/10.1002/hyp.10811, 2016.

Lin, H.: Linking principles of soil formation and flow regimes, J. Hydrol., 393, 3-19, https://doi.org/10.1016/j.jhydrol.2010.02.013, 2010.

Lin, H., Bouma, J., Pachepsky, Y., Western, A., Thompson, J., van Genuchten, R., Vogel, H.-J., and Lilly, A.: Hydropedology: Synergistic integration of pedology and hydrology, Water Resour. Res., 42, 2509-13, https://doi.org/10.1029/2005WR004085, 2006.

Loritz, R., Hassler, S. K., Jackisch, C., Allroggen, N., van Schaik, L., Wienhöfer, J., and Zehe, E.: Picturing and modeling catchments by representative hillslope, Hydrol. Earth Syst. Sci., 21, 1225-1249, https://doi.org/10.5194/hess-21-1225-2017, 2017.

Loritz, R., Gupta, H., Jackisch, C., Westhoff, M., Kleidon, A., Ehret, U., and Zehe, E.: On the dynamic nature of hydrological similarity, Hydrol. Earth Syst. Sci., 22, 3663-3684, https://doi.org/10.5194/hess-22-3663-2018, 2018.

Mizrahi, M.: Hypothesis Testing in Scientific Practice: An Empirical Study, Int. Stud. Philos. Sci., 33, 1-21, https://doi.org/10.1080/02698595.2020.1788348, 2020.

Nearing, G. S., Tian, Y., Gupta, H. V., Clark, M. P., Harrison, K. W., and Weijs, S. V.: A philosophical basis for hydrological uncertainty, 61, 1666-1678, https://doi.org/10.1080/02626667.2016.1183009, 2016.

Neuper, M. and Ehret, U.: Quantitative precipitation estimation with weather radar using a data- and informationbased approach, Hydrol. Earth Syst. Sci., 23, 3711-3733, https://doi.org/10.5194/hess-23-3711-2019, 2019.

Nimmo, J. R.: Quantitative Framework for Preferential Flow Initiation and Partitioning, Vadose Zone J., 15, 1-12, https://doi.org/10.2136/vzj2015.05.0079, 2016.

Peters-Lidard, C. D., Clark, M., Samaniego, L., Verhoest, N. E. C., van Emmerik, T., Uijlenhoet, R., Achieng, K., Franz, T. E., and Woods, R.: Scaling, similarity, and the fourth paradigm for hydrology, Hydrol. Earth Syst. Sci., 21, 3701-3713, https://doi.org/10.5194/hess-21-3701-2017, 2017.

Pfister, L. and Kirchner, J. W.: Debates - Hypothesis testing in hydrology: Theory and practice, Water Resour. Res., 53, 17921798, https://doi.org/10.1002/2016WR020116, 2017.

Phillips, J. D.: Self-organization and landscape evolution, Prog. Phys. Geogr., 19, 309-321, https://doi.org/10.1177/030913339501900301, 2016.

Ploum, S. W., Laudon, H., Peralta-Tapia, A., and Kuglerová, L.: Are dissolved organic carbon concentrations in riparian groundwater linked to hydrological pathways in the boreal forest?, Hydrol. Earth Syst. Sci., 24, 1709-1720, https://doi.org/10.5194/hess-241709-2020, 2020.

Reggiani, P., Sivapalan, M., and Hassanizadeh, S. M.: A unifying framework for watershed thermodynamics: balance equations for mass, momentum, energy and entropy, and the sec- 
ond law of thermodynamics, Adv. Water Resour., 22, 367-398, https://doi.org/10.1016/S0309-1708(98)00012-8, 1998.

Renner, M., Brenner, C., Mallick, K., Wizemann, H.-D., Conte, L., Trebs, I., Wei, J., Wulfmeyer, V., Schulz, K., and Kleidon, A.: Using phase lags to evaluate model biases in simulating the diurnal cycle of evapotranspiration: a case study in Luxembourg, Hydrol. Earth Syst. Sci., 23, 515-535, https://doi.org/10.5194/hess23-515-2019, 2019.

Rodriguez-Iturbe, I. and Rinaldo, A.: Fractal River Basins Chance and Self-Organization, 1 st Edn., Cambridge University Press, Cambridge, UK, 1997.

Roebroek, C. T. J., Melsen, L. A., Hoek van Dijke, A. J., Fan, Y., and Teuling, A. J.: Global distribution of hydrologic controls on forest growth, Hydrol. Earth Syst. Sci., 24, 4625-4639, https://doi.org/10.5194/hess-24-4625-2020, 2020.

Rosenberg, D. E., Filion, Y., Teasley, R., Sandoval-Solis, S., Hecht, J. S., van Zyl, J. E., McMahon, G. F., Horsburgh, J. S., Kasprzyk, J. R., and Tarboton, D. G.: The Next Frontier: Making Research More Reproducible, J. Water Resour. Pl. Manage., 146, 01820002, https://doi.org/10.1061/(ASCE)WR.19435452.0001215, 2020.

Sivapalan, M.: Prediction in ungauged basins: a grand challenge for theoretical hydrology, Hydrol. Process., 17, 3163-3170, https://doi.org/10.1002/hyp.5155, 2003.

Sivapalan, M.: Pattern, Process and Function: Elements of a Unified Theory of Hydrology at the Catchment Scale, in: chap. 13 in the Encyclopedia of Hydrological Sciences, Part 1. Theory, Organization and Scale, John Wiley \& Sons, Ltd., https://doi.org/10.1002/0470848944, 2006.

Stagge, J. H., Rosenberg, D. E., Abdallah, A. M., Akbar, H., Attallah, N. A., and James, R.: Assessing data availability and research reproducibility in hydrology and water resources, Scient. Data, 6, 190030, https://doi.org/10.1038/sdata.2019.30, 2019.

Vogel, H. J. and Roth, K.: A new approach for determining effective soil hydraulic functions, Eur. J. Soil Sci., 49, 547-556, https://doi.org/10.1046/j.1365-2389.1998.4940547.x, 1998.

Wagener, T., Sivapalan, M., Troch, P. A., McGlynn, B. L., Harman, C. J., Gupta, H. V., Kumar, P., Rao, P. S. C., Basu, N. B., and Wilson, J. S.: The future of hydrology: An evolving science for a changing world, Water Resour. Res., 46, W05301, https://doi.org/10.1029/2009WR008906, 2010.

Wagener, T., Gleeson, T., Coxon, G., Hartmann, A., Howden, N., Pianosi, F., Rahman, M., Rosolem, R., Stein, L., and Woods, R.: On doing large-scale hydrology with Lions: Realizing the value of perceptual models and knowledge accumulation, EarthArXiv: preprint, 1-21, https://doi.org/10.31223/osf.io/zdy5n, 2020.
Ward, A. S., Wondzell, S. M., Schmadel, N. M., Herzog, S., Zarnetske, J. P., Baranov, V., Blaen, P. J., Brekenfeld, N., Chu, R., Derelle, R., Drummond, J., Fleckenstein, J. H., GarayburuCaruso, V., Graham, E., Hannah, D., Harman, C. J., Hixson, J., Knapp, J. L. A., Krause, S., Kurz, M. J., Lewandowski, J., Li, A., Martí, E., Miller, M., Milner, A. M., Neil, K., Orsini, L., Packman, A. I., Plont, S., Renteria, L., Roche, K., Royer, T., Segura, C., Stegen, J., Toyoda, J., Wells, J., and Wisnoski, N. I.: Spatial and temporal variation in river corridor exchange across a 5th-order mountain stream network, Hydrol. Earth Syst. Sci., 23, 5199-5225, https://doi.org/10.5194/hess-23-5199-2019, 2019a.

Ward, A. S., Zarnetske, J. P., Baranov, V., Blaen, P. J., Brekenfeld, N., Chu, R., Derelle, R., Drummond, J., Fleckenstein, J. H., Garayburu-Caruso, V., Graham, E., Hannah, D., Harman, C. J., Herzog, S., Hixson, J., Knapp, J. L. A., Krause, S., Kurz, M. J., Lewandowski, J., Li, A., Martí, E., Miller, M., Milner, A. M., Neil, K., Orsini, L., Packman, A. I., Plont, S., Renteria, L., Roche, K., Royer, T., Schmadel, N. M., Segura, C., Stegen, J., Toyoda, J., Wells, J., Wisnoski, N. I., and Wondzell, S. M.: Colocated contemporaneous mapping of morphological, hydrological, chemical, and biological conditions in a 5th-order mountain stream network, Oregon, USA, Earth Syst. Sci. Data, 11, 15671581, https://doi.org/10.5194/essd-11-1567-2019, $2019 \mathrm{~b}$.

Wilkinson, M. D., Dumontier, M., Aalbersberg, I. J., Appleton, G., Axton, M., Baak, A., Blomberg, N., Boiten, J.-W., da Silva Santos, L. B., Bourne, P. E., Bouwman, J., Brookes, A. J., Clark, T., Crosas, M., Dillo, I., Dumon, O., Edmunds, S., Evelo, C. T., Finkers, R., Gonzalez-Beltran, A., Gray, A. J. G., Groth, P., Goble, C., Grethe, J. S., Heringa, J., Hoen, P. A. C. T., Hooft, R., Kuhn, T., Kok, R., Kok, J., Lusher, S. J., Martone, M. E., Mons, A., Packer, A. L., Persson, B., RoccaSerra, P., Roos, M., van Schaik, R., Sansone, S.-A., Schultes, E., Sengstag, T., Slater, T., Strawn, G., Swertz, M. A., Thompson, M., van der Lei, J., van Mulligen, E., Velterop, J., Waagmeester, A., Wittenburg, P., Wolstencroft, K., Zhao, J., and Mons, B.: Comment: The FAIR Guiding Principles for scientific data management and stewardship, Scient. Data, 3, 160018, https://doi.org/10.1038/sdata.2016.18, 2016.

Zehe, E., Ehret, U., Pfister, L., Blume, T., Schröder, B., Westhoff, M., Jackisch, C., Schymanski, S. J., Weiler, M., Schulz, K., Allroggen, N., Tronicke, J., van Schaik, L., Dietrich, P., Scherer, U., Eccard, J., Wulfmeyer, V., and Kleidon, A.: HESS Opinions: From response units to functional units: a thermodynamic reinterpretation of the HRU concept to link spatial organization and functioning of intermediate scale catchments, Hydrol. Earth Syst. Sci., 18, 4635-4655, https://doi.org/10.5194/hess-18-4635-2014, 2014. 